Pacific Journal of Mathematic 


\section{SOME THEOREMS ON BERNOULLI NUMBERS OF HIGHER ORDER}

L. CAR LIT Z

1. Introduction. We define the Bernoulli numbers of order $k$ by means of [3, Chapter 6]

$$
\left(\frac{t}{e^{t}-1}\right)^{k}=\sum_{m=0}^{\infty} \frac{t^{m}}{m !} B_{m}^{(k)}
$$

in particular, $B_{m}=B_{m}^{(1)}$ denotes the ordinary Bernoulli number. Not much seems to be known about divisibility properties of $B_{m}^{(k)}$. Using different notation, $S$. Wachs [4] proved a result which may be stated in the form

$$
B_{p+2}^{(p+1)} \equiv 0 \quad\left(\bmod p^{2}\right)
$$

where $p$ is a prime $\geq 3$. In attempting to simplify Wachs' proof, the writer found the stronger result

$$
B_{p+2}^{(p+1)} \equiv 0 \quad\left(\bmod p^{3}\right)
$$

$$
(p>3) \text {. }
$$

We remark that $B_{5}^{(4)}=-9$.

The proof of (1.2) depends on some well-known properties of the Bernoulli numbers and factorial coefficients; in particular, we make use of some theorems of Glaisher and Nielsen. The necessary formulas are collected in $\$ 2$; the proof of (1.2) is given in $\S 3$. In $\S 4$ we prove

$$
B_{p}^{(p)} \equiv \frac{1}{2} p^{2} \quad\left(\bmod p^{3}\right)
$$

the prous of this result is somewhat simpler than that of (1.2). For the residue of $B_{p}^{(p)}\left(\bmod p^{4}\right)$, see $(4.5)$ below.

In $\$ 5$ we prove several formulas of a similar nature $(p>3)$ : 


$$
\begin{aligned}
& B_{p+1}^{(p)} \equiv-p \frac{B_{p+1}}{p+1}+\frac{1}{24} p^{2} \quad\left(\bmod p^{3}\right), \\
& B_{p+2}^{(p)} \equiv p^{2} \frac{B_{p+1}}{p+1} \quad\left(\bmod p^{4}\right), \\
& B_{p+1}^{(p+1)} \equiv \frac{B_{p+1}}{p+1}-\frac{1}{24} p \quad\left(\bmod p^{2}\right) .
\end{aligned}
$$

In $\$ 6$ we discuss the number $B_{m}^{(p)}$ for arbitrary $m$; this requires the consideration of a number of cases. In particular, we mention the following special results $(p>3)$ :

$$
\underset{p^{r}}{B^{(p)}} \equiv-\frac{1}{2} p^{r+1}(p-1) B_{p^{r-1}} \quad\left(\bmod p^{r+2}\right)
$$

for $r>1$;

$$
B_{m}^{(p)} \equiv \frac{1}{2} p(p-1) B_{m-1} \quad\left(\bmod p^{r+2}\right)
$$

for $m \equiv 1\left(\bmod p^{r}(p-1)\right)$.

It also follows from the results of $\$ 6$ that $B_{m}^{(p)}$ is integral $(\bmod p), p \geq 3$, unless $m \equiv 0(\bmod p-1)$ and $m \equiv 0$ or $p-1(\bmod p)$, in which case $p B_{m}^{(\bar{p})}$ is integral.

The number $B_{m}^{(p+1)}$ requires a more detailed discussion than $B_{m}^{(p)}$; this will be omitted from the present paper. However, we note the special formula

$$
B_{p^{r}}^{(p+1)} \equiv p^{r}\left\{\frac{1}{2} p(p+1) \frac{B_{p^{r}-1}}{p^{r}-1}+p ! \frac{B_{p^{r}-p}}{p^{r}-p}\right\} \quad\left(\bmod p^{r+2}\right)
$$

for $p>3, r>1$. The residue $\left(\bmod p^{r+3}\right)$ can be specified.

2. Some preliminary results. We first state a number of formulas involving $B_{m}^{(k)}$ which may be found in [3, Chapter 6].

$$
\begin{aligned}
& B_{m}^{(k+1)}=(k+1)\left(\begin{array}{c}
m \\
k+1
\end{array}\right) \sum_{s=0}^{k}(-1)^{k-s}\left(\begin{array}{l}
k \\
s
\end{array}\right) B_{s}^{(k+1)} \frac{B_{m-s}}{m-s}, \\
& (x-1)(x-2) \cdots(x-m)=\sum_{s=0}^{m}\left(\begin{array}{l}
m \\
s
\end{array}\right) B_{s}^{(m+1)} x^{m-s} .
\end{aligned}
$$


We shall require the special values

$$
B_{1}^{(k)}=-\frac{1}{2} k, B_{2}^{(k)}=\frac{1}{12} k(3 k-1), B_{3}^{(k)}=-\frac{1}{8} k^{2}(k-1) .
$$

If we define the factorial coefficients by means of

$$
(x+1) \cdots(x+m-1)=\sum_{s=0}^{m-1} C_{s}^{(m)} x^{m-1-s},
$$

we see at once that

$$
(-1)^{s}\left(\begin{array}{c}
m \\
s
\end{array}\right) B_{s}^{(m+1)}=C_{s}^{(m+1)}
$$

We have also the recurrence formula

$$
C_{s}^{(m+1)}=C_{s}^{(m)}+m C_{s-1}^{(m)}
$$

In the next place $[1, \mathrm{p} .325 ; 2, \mathrm{p} .328]$ for $p$ a prime $>3$,

$$
C_{2 r}^{(p)} \equiv-p \frac{B_{2 r}}{2 r}\left(\bmod p^{2}\right) \quad(2 \leq 2 r \leq p-3)
$$

$$
C_{2 r+1}^{(p)} \equiv p^{2} \frac{(2 r+1) B_{2 r}}{4 r} \quad\left(\bmod p^{3}\right)
$$

$$
C_{p-1}^{(p)}=(p-1) ! \equiv p\left(-1+B_{p-1}\right) \quad\left(\bmod p^{2}\right) .
$$

It follows immediately from (2.8) and Wilson's theorem that

$$
p(p+1) B_{p-1} \equiv(p-1) !\left(\bmod p^{2}\right) .
$$

We shall require the following special case of Kummer's congruence [2, Chapter 14]:

$$
\frac{B_{m+p-1}}{m+p-1} \equiv \frac{B_{m}}{m} \quad(\bmod p) \quad(p-1+m)
$$

also, the Staudt-Clausen theorem [3, 32] which we quote in the following form: 


$$
p B_{m} \equiv-1 \quad(\bmod p)
$$$$
(p-1 \mid m)
$$

A formula of a different sort that will be used is [3, p.146, formula (83)]

$$
B_{m}=-\frac{1}{m} \sum_{s=1}^{m}(-1)^{s}\left(\begin{array}{l}
m \\
s
\end{array}\right) B_{s} B_{m-s}
$$

In particular, replacing $m$ by $2 m$, this becomes

$$
(2 m+1) B_{2 m}+\sum_{t=1}^{m-1}\left(\begin{array}{c}
2 m \\
2 t
\end{array}\right) B_{2 t} B_{2 m-2 t}=0
$$

provided $m>1$, a formula due to Euler. The formula [3, p. 145]

$$
B_{m}^{(k+1)}=\left(1-\frac{m}{k}\right) B_{m}^{(k)}-m B_{m-1}^{(k)}
$$

will also be employed. In particular, we note that

$$
B_{m}^{(m+1)}=(-1)^{m} m !
$$

3. Proof of (1.2). Let $p$ be a prime $>3$. In (2.1), taking $k=p, m=p+2$, we get

$$
\begin{aligned}
B_{p+2}^{(p+1)} & =(p+1)(p+2) \sum_{s=0}^{p}(-1)^{p-s}\left(\begin{array}{l}
p \\
s
\end{array}\right) \frac{B_{p+2-s}}{p+2-s} B_{s}^{(p+1)} \\
& =(p+1)(p+2) \sum_{t=0}^{(p-1) / 2}\left(\begin{array}{c}
p \\
2 t+1
\end{array}\right) \frac{B_{p+1-2 t}}{p+1-2 t} B_{2 t+1}^{(p+1)} \\
& =(p+1)(p+2) A
\end{aligned}
$$

say. We break the sum $A$ into several parts:

$$
A=u_{0}+u_{1}+\sum_{t=2}^{(p-3) / 2} u_{t}+u_{(p-1) / 2}
$$

where 


$$
u_{t}=\left(\begin{array}{c}
p \\
2 t+1
\end{array}\right) B_{2 t+1}^{(p+1)} \quad \frac{B_{p+1-2 t}}{p+1-2 t} \quad(0 \leq t \leq p-1)
$$

Then by (2.2) and (2.3) we have

$$
u_{0}=p B_{1}^{(p+1)} \frac{B_{p+1}}{p+1}=-\frac{1}{2} p B_{p+1}
$$

and

$$
u_{(p-1) / 2}=\frac{1}{2} B_{2} B_{p}^{(p+1)}=-\frac{1}{12} p !
$$

by (2.14). As for $u_{1}$ we have, by (2.3),

$$
\begin{aligned}
\left(\begin{array}{l}
p \\
3
\end{array}\right) B_{3}^{(p+1)} & =-\frac{1}{48} p^{2}(p+1)^{2}(p-1)(p-2) \\
& \equiv-\frac{1}{48}\left(p^{3}+2 p^{2}\right) \quad\left(\bmod p^{4}\right) ;
\end{aligned}
$$

thus, by $(2.8)$,

$$
\begin{aligned}
u_{1} & \equiv-\frac{1}{48}\left(p^{2}+2 p\right) \frac{p B_{p-1}}{p-1} \equiv-\frac{1}{48}\left(p^{2}+2 p\right) \frac{(p-1) !}{p^{2}-1} \\
& \equiv \frac{1}{48}\left(p^{2}+2 p\right)(p-1) ! \quad\left(\bmod p^{3}\right) .
\end{aligned}
$$

In the next place, by (2.4) and (2.5),

$$
\begin{aligned}
\left(\begin{array}{c}
p \\
2 t+1
\end{array}\right) B_{2 t+1}^{(p+1)} & =-C_{2 t+1}^{(p+1)}=-C_{2 t+1}^{(p)}-p C_{2 t}^{(p)} \\
& \equiv-p^{2}\left(\frac{2 t+1}{4 t}-\frac{1}{2 t}\right) B_{2 t} \\
& \equiv-p^{2} \frac{2 t-1}{4 t} B_{2 t} \quad\left(\bmod p^{3}\right)
\end{aligned}
$$

for $2 \leq t \leq(p-3) / 2$. Hence 


$$
u_{t} \equiv p^{2} \frac{B_{2 t}}{4 t} B_{p+1-2 t} \quad\left(\bmod p^{3}\right),
$$

so that

$$
\sum_{t=2}^{(p-3) / 2} u_{t} \equiv p^{2} \sum_{t=2}^{(p-3) / 2} \frac{1}{4 t} B_{2 t} B_{p+1-2 t} \quad\left(\bmod p^{3}\right) .
$$

On the other hand, by (2.12),

$$
(p+2) B_{p+1}+\sum_{t=1}^{(p-1) / 2}\left(\begin{array}{c}
p+1 \\
2 t
\end{array}\right) B_{2 t} B_{p+1-2 t}=0,
$$

which implies

$$
\begin{aligned}
(p+2) B_{p+1}+\frac{1}{6} p(p+1) B_{p-1} & \equiv p(p+1) \sum_{2}^{(p-3) / 2} \frac{B_{2 t}}{2 t} \frac{B_{p+1-2 t}}{p+1-2 t} \\
& \equiv 2 p \sum_{2}^{(p-3) / 2} \frac{1}{2 t} B_{2 t} B_{p+1-2 t} \quad\left(\bmod p^{2}\right) ;
\end{aligned}
$$

the last crngruence is a consequence of

$$
\frac{1}{2 t}+\frac{1}{p+1-2 t} \equiv \frac{1}{2 t(p+1-2 t)} \quad(\bmod p) .
$$

Now using (3.6) we see that

$$
\sum_{2}^{(p-3) / 2} u_{t} \equiv \frac{1}{4} p(p+2) B_{p+1}+\frac{1}{24} p^{2}(p+1) B_{p-1}
$$

$$
\equiv \frac{1}{4} p(p+2) B_{p+1}+\frac{1}{24} p(p-1) ! \quad\left(\bmod p^{3}\right)
$$

by (2.9). Collecting from (3.3), (3.4), (3.5), and (3.7) we get, after some simplification,

$$
A \equiv \frac{1}{4} p^{2} B_{p+1}+\frac{1}{48} p^{2}(p-1) !
$$




$$
\begin{aligned}
& \equiv \frac{1}{4} p^{2}\left(\frac{B_{p+1}}{p+1}-\frac{B_{2}}{2}\right)+\frac{1}{48} p^{2}+\frac{1}{48} p^{2}(p-1) ! \\
& \equiv 0 \quad\left(\bmod p^{3}\right)
\end{aligned}
$$

by (2.10). Therefore, by $(3.1), B_{p+2}^{(p+1)} \equiv 0\left(\bmod p^{3}\right)$.

It would be of interest to determine the residue of $B_{p+2}^{(p+1)}\left(\bmod p^{4}\right)$. We have already noted that $B_{5}^{(4)} \not \equiv 0\left(\bmod 3^{3}\right)$; for small $p$ at least, it can be verified that $B_{p+2}^{(p+1)} \not \equiv 0\left(\bmod p^{4}\right)$.

4. Proof of (1.3). We now take $m=p>3, k=p-1$ in (2.1), so that

$$
B_{p}^{(p)}=p \sum_{s=0}^{p-1}(-1)^{s}\left(\begin{array}{c}
p-1 \\
s
\end{array}\right) \frac{B_{p-s}}{p-s} B_{s}^{(p)}
$$

$$
=p\left\{\frac{1}{2} p B_{p-1}-\frac{1}{2}(p-1) !-\sum_{t=1}^{(p-3) / 2}\left(\begin{array}{c}
p-1 \\
2 t+1
\end{array}\right) \frac{B_{p-1-2 t}}{p-1-2 t} B_{2 t+1}^{(p)}\right\}
$$

by (2.3) and (2.4). Now, again using (2.4), we have

$$
\begin{aligned}
\left(\begin{array}{c}
p-1 \\
2 t+1
\end{array}\right) B_{2 t+1}^{(p)} & =-C_{2 t+1}^{(p)} \\
& \equiv-p^{2} \frac{(2 t+1) B_{2 t+1}}{4 t} \quad\left(\bmod p^{3}\right)
\end{aligned}
$$

Hence, the sum $Q$ in the right member of (4.1) satisfies $Q \equiv 0\left(\bmod p^{2}\right)$; more precisely, we see that

$$
Q \equiv p^{2} \sum_{1}^{(p-3) / 2} \frac{1}{4 t} B_{2 t} B_{p-1-2 t}\left(\bmod p^{3}\right)
$$

to which we return presently. Thus, it is clear that (4.1) reduces to

$$
B_{p}^{(p)} \equiv \frac{p}{2}\left(p B_{p-1}-(p-1) !\right) \quad\left(\bmod p^{3}\right)
$$

But by (2.8) this implies

$$
B_{p}^{(p)} \equiv \frac{1}{2} p^{2} \quad\left(\bmod p^{3}\right)
$$


Since $B_{3}^{(3)}=-9 / 4 \equiv 9 / 2(\bmod 27),(4.3)$ holds for $p \geq 3$.

To determine the residue of $B_{p}^{(p)}\left(\bmod p^{4}\right)$ we make use of $[2, \mathrm{p} .366$, formula (10)],

$$
\sum_{t=1}^{(p-3) / 2} \frac{1}{2 t} B_{2 t} B_{p-1-2 t} \equiv \frac{1}{p}\left(W_{p}-K_{p}\right)-W_{p} \quad(\bmod p),
$$

where $W_{p}^{\prime}, K_{p}$ are defined by

$$
\begin{aligned}
& (p-1) !+1=p W_{p}, \quad a^{p-1}-1=p k(a) \quad(p \nmid a), \\
& K_{p}=k(1)+k(2)+\cdots+k(p-1) .
\end{aligned}
$$

Then, by (4.1) and (4.2),

$$
B_{p}^{(p)} \equiv \frac{1}{2} p\left\{p R_{p-1}+1-p K_{p}-p^{2} W_{p}\right\} \quad\left(\bmod p^{4}\right)
$$

since $W_{p} \equiv K_{p}(\bmod p)$, this may also be put in the form

$$
B_{p}^{(p)} \equiv \frac{1}{2} p^{2}\left\{B_{p-1}+\frac{1}{p}-(p+1) K_{p}\right\} \quad\left(\bmod p^{4}\right) .
$$

That (4.5) includes (4.3) is easily verified.

5. Proof of (1.4), (1.5), (1.6). In the remainder of the paper let $p>3$. In (2.13) take $k=p, m=p+2$; then

$$
B_{p+2}^{(p+1)}=\left(1-\frac{p+2}{p}\right) B_{p+2}^{(p)}-(p+2) B_{p+1}^{(p)}
$$

Therefore, by (1.2),

$$
\frac{2}{p} B_{p+2}^{(p)}+(p+2) B_{p+1}^{(p)} \equiv 0 \quad\left(\bmod p^{3}\right)
$$

Now take $k=p-1, m=p+2$ in (2.1), so that

$$
B_{p+2}^{(p)}=p\left(\begin{array}{c}
p+2 \\
p
\end{array}\right) \sum_{s=0}^{p-1}(-1)^{s}\left(\begin{array}{c}
p-1 \\
s
\end{array}\right) B_{s}^{(p)} \frac{B_{p+2-s}}{p+2-s} .
$$

Clearly only odd values of $s$ need be considered; we get, using (2.4), 


$$
\begin{aligned}
B_{p+2}^{(p)} & =(p+2)\left(\begin{array}{c}
p+1 \\
p-1
\end{array}\right) \sum_{t=0}^{(p-3) / 2} C_{2 t+1}^{(p)} \frac{B_{p+1-2 t}}{p+1-2 t} \\
& \equiv(p+2)\left(\begin{array}{l}
p+1 \\
p-1
\end{array}\right)\left(-\frac{1}{2} p \frac{B_{p+1}}{p+1}+\frac{1}{8} p^{2} \frac{B_{p-1}}{p-1}\right) \quad\left(\bmod p^{3}\right)
\end{aligned}
$$

by (2.3) and (2.7); next, by (2.9) and (2.10), we get

$$
B_{p+2}^{(p)} \equiv \frac{1}{12} p^{2} \quad\left(\bmod p^{3}\right)
$$

In view of (5.1) we have also

$$
B_{p+1}^{(p)} \equiv-\frac{1}{12} p \quad\left(\bmod p^{2}\right) .
$$

However, (5.2) and (5.3) do not imply (5.1) but only the weaker result with modulus $p^{2}$.

To improve these results we follow the method of $\$ 3$. Thus

$$
B_{p+1}^{(p)}=p(p+1) \sum_{s=0}^{(p-1) / 2} C_{2 s}^{(p)} \frac{B_{p+1-2 s}}{p+1-2 s}=p(p+1) A,
$$

and

$$
A=\frac{B_{p+1}}{p+1}+C_{2}^{(p)} \frac{B_{p-1}}{p-1}+\sum_{t=2}^{(p-3) / 2} C_{2 t}^{(p)} \frac{B_{p+1-2 t}}{p+1-2 t}+\frac{1}{12}(p-1) ! .
$$

But, by (3.61),

$$
\begin{gathered}
\sum_{t=2}^{(p-3) / 2} C_{2 t}^{(p)} \frac{B_{p+1-2 t}}{p+1-2 t} \equiv-p \sum_{2}^{(p-3) / 2} \frac{B_{2 t}}{2 t} \frac{B_{p+1-2 t}}{p+1-2 t} \\
\equiv-\frac{p+2}{p+1} B_{p+1}-\frac{1}{6} p B_{p-1} \quad\left(\bmod p^{2}\right),
\end{gathered}
$$

so that after some simplification we get

$$
A \equiv-\frac{B_{p+1}}{p+1}+\frac{1}{8} p \quad\left(\bmod p^{2}\right),
$$


and therefore, by (5.4) and (2.10),

$$
B_{p+1}^{(p)} \equiv-p \frac{B_{p+1}}{p+1}+\frac{1}{24} p^{2} \quad\left(\bmod p^{3}\right)
$$

In view of (5.1) this implies

$$
B_{p+2}^{(p)} \equiv p^{2} \frac{B_{p+1}}{p+1} \quad\left(\bmod p^{4}\right) .
$$

That (5.5) and (5.6) include (5.3) and (5.2) is evident; also (5.5) and (5.6) imply (1.2).

We remark also that using (2.13), (5.5), and (1.3) we get

$$
B_{p+1}^{(p+1)} \equiv \frac{B_{p+1}}{p+1}-\frac{1}{24} p \quad\left(\bmod p^{2}\right)
$$

6. Discussion of $B_{m}^{(p)}$. Let first $m>p$ be odd, so that (2.1) implies

$$
B_{m}^{(p)}=p\left(\begin{array}{c}
m \\
p
\end{array}\right) \sum_{t=0}^{(p-3) / 2} C_{2 t+1}^{(p)} \frac{B_{m-1-2 t}}{m-1-2 t} .
$$

Now let $m \equiv a(\bmod p), 0 \leq a<p ; m \equiv b(\bmod p-1), 0 \leq b<p-1$. Also, let $p^{r} \mid m-a, p^{r+1} \nmid m-a$, so that the binomial coefficient $\left(\begin{array}{l}m \\ p\end{array}\right)$ is divisible by exactly $p^{r-1}$. Clearly $b$ is odd. Now by a well-known theorem [2, p. 252], if $a \neq b$, the quotient $B_{m-a} /(m-a)$ is integral $(\bmod p)$. Thus, by (2.7), the right member of (6.1), except for the terms corresponding to $t=0,(b-1) / 2$, is a multiple of $p^{r+2}$. As for the exceptional terms

$$
u_{1}=p\left(\begin{array}{c}
m \\
p
\end{array}\right) C_{1}^{(p)} \frac{B_{m-1}}{m-1}, \quad u_{b}=p\left(\begin{array}{c}
m \\
p
\end{array}\right) C_{b}^{(p)} \frac{B_{m-b}}{m-b},
$$

there are several possibilities.

(i) Suppose $b=1$, so that the two terms in (6.2) coincide. Then if $a \neq 1$, we see that the term in question is exactly divisible by $p^{r}$. On the other hand if $a=1$, the term is integral $(\bmod p)$ but not divisible by $p$.

(ii) If $b \neq 1, u_{1}$ and $u_{b}$ in (6.2) are distinct. There are several cases to consider. If $a=b$, then $u_{1}$ is divisible by $p^{r+1}$, while $u_{b}$ is divisible by exactly $p^{r+1}$. Thus, in this sub-case $B_{m}^{(p)}=0\left(\bmod p^{r+1}\right)$; for $m=p+2$ this is less precise than (5.2).

In the next place, let $m$ be even and define $a, b, r$ as above so that $b$ is now 
even.. Then we have

$$
B_{m}^{(p)}=p\left(\begin{array}{l}
m \\
p
\end{array}\right) \quad \sum_{t=0}^{(p-1) / 2} C_{2 t}^{(p)} \frac{B_{m-2 t}}{m-2 t}=\sum_{t=0}^{(p-1) / 2} u_{2 t} .
$$

Then by (2.6) the right member, except for the terms $u_{0}, u_{b}, u_{p-1}$, is a multiple of $p^{r+1}$. We consider a number of cases.

(iii) If $b=0$, there are only two distinct terms $u_{0}, u_{p-1}$. If $a=0$, we find that $p u_{0}$ is integral $(\bmod p) ;$ indeed $p u_{0} \equiv-1(\bmod p)$ by the Staudt-Clausen theorem (2.11). On the other hand, $u_{p-1}$ is divisible by $p^{r-1}$; indeed $u_{p-1} \equiv$ $m /(m-p+1)\left(\bmod p^{r}\right)$. If $a=p-1$, then $u_{0} \equiv(m-p+1) / m\left(\bmod p^{r}\right)$ while $p u_{p-1} \equiv 1(\bmod p)$. If $a \neq 0$ or $p-1$ then it can be verified that $u_{0}+u_{p-1}$ is divisible by $p^{r}$.

(iv) If $b \neq 0$, then all three terms $u_{0}, u_{b}, u_{p-1}$ are distinct. By means of Kummer's congruence $(2.10)$ we find that $u_{0}+u_{p-1} \equiv 0\left(p^{r+1}\right)$; in other words;

$$
B_{m}^{(p)} \equiv u_{b} \quad\left(\bmod p^{r+1}\right)
$$

As for $u_{b}$, there are several possibilities. If $a=b$, it is easily seen that $u_{b}$ is integral $(\bmod p)$; moreover, by $(2.6), u_{b} \equiv 0(\bmod p)$ if and only if $B_{b} \equiv 0$ $(\bmod p)$. If $a \neq b$, then $u_{b}$ is divisible by $p^{r}$ at least; indeed using (6.4) we get

$$
B_{m}^{(p)} \equiv B_{b} \frac{m-a}{b(m-b)} \quad\left(\bmod p^{r+1}\right) \quad(a \neq b, b \neq 0) .
$$

This result evidently includes (5.3) but not (5.5).

We remark that $B_{m}^{(p)}$ is integral $(\bmod p)$ in cases (i), (ii), (iv). In case (iii), however, if $a=0$ or $p-1$, then $B_{m}^{(p)}$ is no longer integral, but $p B_{m}^{(p)}$ is integral; indeed it is easily verified that

$$
\begin{aligned}
& p B_{m}^{(p)} \equiv \begin{cases}-1 & (\bmod p) \\
+1 & (\bmod p)\end{cases} \\
& (a=0), \\
& (a=p-1) .
\end{aligned}
$$

7. Some special cases. Clearly $m=p^{r}, r>1$, falls under (i) above with $a=0, b=1$. Thus,

$$
B_{p^{r}}^{(p)} \equiv-\frac{1}{2} p^{r-1}(p-1) B_{p^{r-1}} \quad\left(\bmod p^{r+2}\right)
$$

and in particular, 


$$
B_{p^{r}}^{(p)} \equiv-\frac{1}{2} p^{r} \quad\left(\bmod p^{r+1}\right)
$$

For $m \equiv 1\left(\bmod p^{r}(p-1)\right)$, we have $a=b=1$ which also falls under (i); we now have

$$
B_{m}^{(p)}=\frac{1}{2}(p-1) p B_{m-1} \quad\left(\bmod p^{r+2}\right)
$$

For $m=c p^{r}$, where $c$ is odd, $p \nmid c$, we have $a=0, c \equiv b(\bmod p-1)$, which evidently falls under (i) or (ii). Thus, we get $(r \geq 1)$

$$
B_{c p^{r}}^{(p)}=\frac{1}{2} c p^{r+1} \frac{p-1}{c p^{r}-1} B_{c p^{r-1}} \quad\left(\bmod p^{r+2}\right)
$$

for $c \equiv 1(\bmod p-1)$;

$$
B_{c p^{r}}^{(p)} \equiv-\frac{1}{2} c p^{r+1}\left(B_{c p^{r-b}}+\frac{1}{b-1}\right) \quad\left(\bmod p^{r+2}\right)
$$

for $c \equiv b(\bmod p-1), b \neq 1$.

Similarly, for $m=c p^{r}, c$ even, $p \nmid c$, we have $a=0, c \equiv b(\bmod p-1)$, which falls under (iii) or (iv). We consider only the case $p-1 \nmid c$; that is, $b \neq 0$. Then, by $(6.5)$, we have

$$
B_{c p^{r}}^{(p)} \equiv-\frac{c}{b^{2}} p^{r} B_{b} \quad\left(\bmod p^{r+1}\right)
$$

Again for $m=c p^{r}+a, c$ odd, $a$ even, we find

$$
B_{m}^{(p)} \equiv \frac{1}{2} c p^{r+1}(p-1) \frac{B_{m-1}}{m-1} \quad\left(\bmod p^{r+2}\right)
$$

for $b=1$, while

$$
B_{m}^{(p)} \equiv-\frac{1}{2} c p^{r+1}\left(\frac{B_{m-1}}{a-1}-\frac{b}{(b-1)(b-a)}\right) \quad\left(\bmod p^{r+2}\right)
$$

for $b \neq 1$; in these two formulas we have $0<a<p-1, b \equiv c+a(\bmod p-1)$. For $c$ even, $a$ odd, (7.7) holds; but (7.8) requires modification. For $c$ and $a$ both odd or both even, there are several cases; in particular, by (6.5) we have 


$$
B_{m}^{(p)} \equiv \frac{c p}{b(a-b)} \quad\left(\bmod p^{r+1}\right)
$$

for $a \neq b, b \neq 0$.

For $p=2,3$ it follows at once from (2.1) that

$$
\begin{gathered}
B_{m}^{(2)}=-m(m-1)\left(\frac{B_{m}}{m}+\frac{B_{m-1}}{m-1}\right), \\
B_{m}^{(3)}=\frac{1}{2} m(m-1)(m-2)\left(\frac{B_{m}}{m}+3 \frac{B_{m-1}}{m-1}+2 \frac{B_{m-2}}{m-2}\right),
\end{gathered}
$$

by means of which numerous special formulas can easily be obtained, for example,

$$
\begin{array}{ll}
B_{m}^{(2)}= \begin{cases}-(m-1) B_{m} & (m \text { even }>2), \\
-m B_{m-1} & (m \text { odd })\end{cases} \\
B_{m}^{(3)}=\frac{3}{2} m(m-2) B_{m-1} & (m \text { odd }>1) .
\end{array}
$$

\section{REFERENCES}

1. J. W. L. Glaisher, On the residues of the sums of products of the first $p-1$ numbers, and their powers, to modulus $p^{2}$ or $p^{3}$, Quarterly Journal of Pure and Applied Mathematics, 31 (1900), $321-353$.

2. Niels Nielsen, Traité élémentaire des nombres de Bernoulli, Paris, (1923).

3. N. E. Nörlund, Vorlesungen über Differenzenrechnung, Berlin, (1924).

4. S. Wachs, Sur une propriété arithmétique des nombres de Cauchy, Bull. Sci. Math. (2) 71 (1947), 219-232.

DUKe UNIVERSITY 



\section{PACIFIC JOURNAL OF MATHEMATICS}

\section{EDITORS}

R. M. RoBINSON

University of California Berkeley 4, California

\section{*R. P. Dilworth}

Califomia Institute of Technology Pasadena 4, California

\section{E. F. BECKENBACH, Managing Editor}

University of California

Los Angeles 24, California

*During the absence of Herbert Busemann in 1952.

\section{ASSOCIATE EDITORS}

\author{
R. P. DILWORTH \\ HERBERT FEDERER \\ MARSHALL HALL
}

\author{
P. R. HALMOS \\ HEINZ HOPF
}

R. D. JAMES

\author{
BØRGE JESSEN \\ PAUL LÉVY \\ GEORGE PÓLYA
}

\author{
J. J. STOKER \\ E. G. STRAUS
}

KÖSAKU YOSIDA

\section{SPONSORS}

UNIVERSITY OF BRITISH COLUMBIA

CALIFORNIA INSTITUTE OF TECHNOLOGY

UNIVERSITY OF CALIFORNIA, BERKELEY

UNIVERSITY OF CALIFORNIA, DAVIS

UNIVERSITY OF CALIFORNIA, LOS ANGELES

UNIVERSITY OF CALIFORNIA, SANTA BARBARA

OREGON STATE COLLEGE

UNIVERSITY OF OREGON

\author{
UNIVERSITY OF SOUTHERN CALIFORNIA \\ STANFORD UNIVERSITY \\ WASHINGTON STATE COLLEGE \\ UNIVERSITY OF WASHINGTON \\ AMERICAN MATHEMATICAL SOCIETY \\ NATIONAL BUREAU OF STANDARDS, \\ INSTITUTE FOR NUMERICAL ANALYSIS
}

Mathematical papers intended for publication in the Pacific Journal of Miathematics should be typewritten (double spaced), and the author should keep a complete copy. Manuscripts may be sent to any of the editors. All other communications to the editors should be addressed to the managing editor, E. F. Beckenbach, at the address given above.

Authors are entitled to receive 100 free reprints of their published papers and may obtain additional copies at cost.

The Pacific Journal of Mathematics is published quarterly, in March, June, September, and December, by the University of California, Berkeley 4, California. The price per volume (4 numbers) is $\$ 8.00$; single issues, $\$ 2.50$. Special price to individual faculty members of supporting institutions and to individual members of the American Mathematical Society: $\$ 4.00$ per volume; single issues, $\$ 1.25$.

Subscriptions, orders for back numbers, and changes of address should be sent to the publishers, University of California Press, Berkeley 4, California.

Printed at Ann Arbor, Michigan. Entered as second class matter at the Post Office, Berkeley, California.

\section{UNIVERSITY OF CALIFORNIA PRESS • BERKELEY AND LOS ANGELES}




\section{Pacific Journal of Mathematics}

\section{Vol. 2, No. $2 \quad$ February, 1952}

L. Carlitz, Some theorems on Bernoulli numbers of higher order...

Watson Bryan Fulks, On the boundary values of solutions of the heat equation........................................ 141

John W. Green, On the level surfaces of potentials of masses with fixed center of gravity................................... 147

Isidore Heller, Contributions to the theory of divergent series .......... 153

Melvin Henriksen, On the ideal structure of the ring of entire functions . . . 179

James Richard Jackson, Some theorems concerning absolute neighborhood retracts........................................ 185

Everett H. Larguier, Homology bases with applications to local connectedness ................................... 191

Janet McDonald, Davis's canonical pencils of lines ................ 209

J. D. Niblett, Some hypergeometric identities . . . . . . . . . . . . . . . . . . 219

Elmer Edwin Osborne, On matrices having the same characteristic equation...................................... 227

Robert Steinberg and Raymond Moos Redheffer, Analytic proof of the

Lindemann theorem ................................. 231

Edward Silverman, Set functions associated with Lebesgue area ......... 243

James G. Wendel, Left centralizers and isomorphisms of group algebras . . 251

Kosaku Yosida, On Brownian motion in a homogeneous Riemannian space. 